\title{
Effectiveness of an educational intervention on complementary feeding practices and growth in rural China: a cluster randomised controlled trial
}

\author{
Ling Shi ${ }^{1, *}$, Jingxu Zhang ${ }^{2}$, Yan Wang ${ }^{2}$, Laura E Caulfield ${ }^{3}$ and Bernard Guyer ${ }^{4}$ \\ ${ }^{1}$ College of Nursing and Health Sciences, University of Massachusetts - Boston, Boston, MA 02125, USA: \\ ${ }^{2}$ Department of Child, Adolescent and Women's Health, Peking University Health Science Center, Beijing, \\ People's Republic of China: ${ }^{3}$ Department of International Health, Johns Hopkins Bloomberg School of Public \\ Health, Baltimore, MD, USA: ${ }^{4}$ Department of Population, Family and Reproductive Health, Johns Hopkins \\ Bloomberg School of Public Health, Baltimore, MD, USA
}

Submitted 25 March 2009: Accepted 20 July 2009: First published online 26 August 2009

\begin{abstract}
Objective: Inappropriate complementary feeding is one of the major causes of malnutrition in young children in developing countries. We developed an educational intervention, delivered by local health-care providers, aimed at improving complementary feeding practices and child nutrition.

Design: Eight townships in Laishui, a rural area in China, were randomly assigned to the educational intervention or control group. A total of 599 healthy infants were enrolled at age 2-4 months and followed up until 1 year of age. In the intervention group, educational messages and enhanced home-prepared recipes were disseminated to caregivers through group trainings and home visits. Questionnaire surveys and anthropometric measurements were taken at baseline and ages 6, 9 and 12 months. Analysis was by intention to treat.

Results: It was found that food diversity, meal frequency and hygiene practices were improved in the intervention group. Infants in the intervention group gained $0.22 \mathrm{~kg}$ more weight (95\% CI $0.003,0.45 \mathrm{~kg}, P=0.047)$ and gained $0.66 \mathrm{~cm}$ more length (95\% CI $0 \cdot 03,1 \cdot 29 \mathrm{~cm}, P=0 \cdot 04)$ than did controls over the study period. Conclusions: Findings from the study suggest that an educational intervention delivered through local health-care providers can lead to substantial behavioural changes of caregivers and improve infant growth.
\end{abstract}

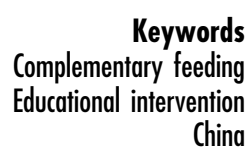

Inappropriate complementary feeding practices, such as too early introduction of complementary foods, restriction in food selection and insufficient amounts of complementary foods, have been identified as one of the major causes of malnutrition in young children in the developing world ${ }^{(1,2)}$. In China, for example, despite the rapid pace of social and economic development, poor complementary feeding practices remain prevalent in rural areas. Rural children are often given food that is mainly carbohydrate and low in protein and fat ${ }^{(3)}$. Less than a quarter of infants and young children in rural China consume dairy and animal-source foods daily ${ }^{(4)}$, and about $15 \%$ of young children have never been fed meat, eggs or bean products ${ }^{(5)}$. Previous studies have found that caregivers do not give available quality foods such as meats, vegetables, oil and eggs to infants because of traditional beliefs that these foods are too 'heavy' for infants to digest ${ }^{(6,7)}$. The poor complementary feeding practices in rural areas have resulted in great disparities in growth and nutritional status between rural and urban children. Data from the Chinese Child Nutrition Surveillance Programme show that the prevalence of stunting in rural children was $20.5 \%$ in 2000 , much higher than that of $2 \cdot 9 \%$ among their urban counterparts ${ }^{(8)}$. The prevalence of underweight was highest between 6 and 24 months of age, with $13.9 \%$ of rural children being underweight compared with $3 \cdot 0 \%$ of children living in cities $^{(8)}$.

Effective interventions are therefore needed in rural China to improve complementary feeding practices and enhance child nutrition and health. A number of nutrition educational interventions have been carried out in developing countries aimed to provide caregivers with information and motivation to alter feeding practices ${ }^{(2,9-19)}$. These studies provide evidence that educational interventions can improve caregiver feeding practices and child dietary intake $\mathrm{e}^{(2,10,12,14,15,18,19)}$. However there is a paucity of knowledge about how to deal with deep-rooted cultures and traditions through educational interventions. There also remains heterogeneity 
across studies on the impact of these interventions on child growth, thereby hindering the efforts of local, national and international organisations to advocate for such behavioural interventions. Therefore we conducted a randomised controlled trial in rural China to assess the effects of an educational intervention delivered through health-care providers on caregiver feeding practices and child growth.

\section{Methods}

\section{Study area and participants}

The study was conducted in Laishui County of Hebei Province in north-west China, with a population of 340000 and a per capita gross domestic product of \$US 500 in 2006. There is one general hospital and one Maternal and Child Health hospital in the county. Each of the fifteen administrative townships has its own government-funded hospital. Each village also has a doctor trained in modern medicine or traditional medicine.

Eight townships were selected that each had at least two primary health-care providers who could provide intervention and evaluation for the study. Townships were paired based on population, geographic type and economic condition. We avoided pairing up directly adjacent sites. The paired townships were listed alphabetically in blocks of two and assigned randomly to be intervention or control sites.

All infants in the selected townships who were full-term (gestational age $>37$ weeks), singletons, without major birth defects, and aged $2-4$ months at the time of the baseline survey were eligible for the study. The eligible infants and their families were identified through birth registration and household registration, and recruited by local primary health-care providers. Written informed consent was obtained from the children's parents. In total, 599 infants were enrolled between April and September of 2006.

\section{Procedures}

During the developmental stage of the intervention, we reviewed literature to identify previous successful intervention strategies. Existing documents including routine registration, clinical records and survey results were examined to understand the local population, climate, geography, economy, children's morbidity and mortality, malnutrition prevalence and health services. Primary health-care providers were interviewed about local infant feeding patterns, the ingredients and methods of preparation of typical meals for infants, and cultural beliefs regarding food selection and preparation.

Based on the findings from this formative research, we developed an intervention plan comprising four major components: (i) group training sessions on food selection, preparation and hygiene, childhood nutrition and growth, and responsive feeding style; (ii) demonstration of preparing enhanced weaning food recipes which were formulated using locally available, affordable, acceptable and nutrient-dense foods such as egg, tomato, beans, meat, chicken and liver; (iii) booklets which contained infant feeding guidance and methods of preparing the recommended recipes; and (iv) home visits every three months to identify possible feeding problems and provide individual counselling. Important family members, mainly husbands and parents-in-law, and community members such as the village doctors and committee leaders were involved in the intervention so they could provide a supportive environment for changing feeding practices. The control group received a standard package of child health care from the township hospitals which included breast-feeding counselling, but did not contain other than standard counselling on complementary feeding.

Before the initiation of the intervention, the health-care providers in the intervention areas were trained by the study team on child nutrition, breast-feeding, complementary feeding and counselling skills. They then conducted group training sessions with the village committee leaders, child caregivers and key family members on the benefits of breast-feeding, timing of introduction of complementary foods, continued breast-feeding in the first year of age, nutritional value of major foods, symptoms and hazards of childhood malnutrition, and quality and quantity of complementary foods. A demonstration of the preparation of the recommended recipes followed the group training. The recipes were designed based on local typical meals and modified to increase the energy and nutrient density of the diet. For example, a local common food $b u b u$ (Dough Drop Soup), which is made from flour and water, was improved by adding carrot, onion, cabbage, potato, pumpkin, egg and cooking oil. The trained health-care providers explained the benefits of the ingredients in the recipes and showed caregivers how to prepare the recipes. The recipes were then fed to children, and the caregivers were asked to evaluate what they liked or disliked about the recipes, whether they had any difficulty in using the recipe, and if they would use the recipes in future.

A $30 \mathrm{~min}$ questionnaire was administered by local health-care providers to the mothers of the infants at baseline, and 6, 9 and 12 months of age. The questionnaires collected information on infant feeding practices, health status, caregiver's knowledge, beliefs and behaviours, and household sociodemographic background. At the end of each survey questionnaire, the weights and lengths of the infants were measured following standard procedures ${ }^{(20)}$. Infants were weighed in light clothing using electric weight scales with $0 \cdot 01 \mathrm{~kg}$ accuracy. Their supine lengths were measured barefooted and bareheaded using standard infant length boards with $0 \cdot 1 \mathrm{~cm}$ accuracy. Parental weights were measured using electric weight scales to the nearest $0.01 \mathrm{~kg}$, and heights were measured using statiometer to the nearest $0 \cdot 1 \mathrm{~cm}$. The measurements of weight and length/height were 
repeated twice by two trained primary health-care providers cooperatively. Infants' birth weight and length were obtained from birth records.

The major outcomes of the study were caregivers' complementary feeding practices and infants' physical growth. Complementary feeding practices were measured by the following indicators: (i) meal frequency; (ii) the proportions of children consuming a variety of food groups; (iii) caregivers preparing easy-to-digest foods for children; (iv) washing hands before feeding, using soap and clean water; and (v) encouraging the child to eat when the child refuses. Physical growth was assessed by attained weight and length (i.e. observed weight and length at each measurement point) and incremental weight and length (i.e. increase in weight and length between baseline and the final observation point).

\section{Ethics committee approval}

The study was approved by the institutional review boards of the Johns Hopkins Bloomberg School of Public Health and Peking University Health Science Center.

\section{Statistical analysis}

For budget and logistical reasons, we could only enrol four townships per treatment group. There was no information available about inter-cluster coefficient of variation, but we expected the inter-cluster variation to be low at $0 \cdot 01$. Assuming the standard deviation for weight was $1 \mathrm{~kg}$ and average weight was $9 \mathrm{~kg}$ in the control group, to detect a $0.3 \mathrm{~kg}$ difference in weight between the intervention and control groups with $80 \%$ power and $5 \%$ significance level, and to account for the cluster effect and $20 \%$ loss to follow-up, we estimated a sample size of 600 in total (seventy-five per cluster).

Analysis was by intention to treat. Differences between groups were tested first using the Student $t$ test for continuous variables and the $\chi^{2}$ or Fisher exact test for categorical variables, and then using multivariate regression models to control for possible confounding effects of sociodemographic covariates. Township was used as the treatment unit, but the correlation in the outcomes within townships was low at about $0 \cdot 01$ and the within-township correlation was not significant in the random-effect model; therefore we omitted the intra-cluster correlation during final analyses. Random-effect regression models were used to examine the effects of the intervention on growth addressing the correlations among repeated measures on the same subject. Data management and statistical analysis were performed with the Stata statistical software package version $8 \cdot 0$ (Stata Corp., College Station, TX, USA).

\section{Results}

A total of 599 infants were recruited at baseline, 294 in the intervention group and 305 in the control group. Infants in the intervention group did not differ significantly from controls with respect to infant gender, age, birth weight and length, parents' age, ethnicity, education, number of siblings, household possessions, as well as parents' weight and height (Table 1). However, more mothers at intervention sites than controls engaged in agriculture work $(57 \cdot 1 \%$ v. $49.8 \%, P<0.05)$ and more fathers at intervention sites than controls were migrant labourers who worked temporarily in cities $(67 \cdot 3 \% v .55 \cdot 7 \%, P<0.05)$.

Children available for the follow-up visits at 6, 9 and 12 months of age numbered 528 (88.1\%), $473(79 \cdot 0 \%)$ and $490(81 \cdot 8 \%)$, respectively (Fig. 1). The main reasons for loss to follow-up were that the families moved out of the area, decided not to participate or were not at home at the time of the survey.

Summarised in Table 2 are reported infant feeding practices at baseline (2-4 months), 6, 9 and 12 months of age. The two groups were comparable at baseline in terms of current breast-feeding rate, breast-feeding frequency, introduction of complementary foods, and caregivers' hand-washing practice. Breast-feeding practices did not differ between groups at any of the follow-up points. Most infants $(93.6 \%$ in the intervention group and $93.9 \%$ in the control group, $P=0.88$ ) were breast-fed at 6 months. By 1 year of age, $85 \cdot 1 \%$ in the intervention group and $85.4 \%$ in controls were still breast-fed $(P=0.92)$.

Overall, improved complementary feeding practices were observed in the intervention group. A significantly higher proportion of children in the intervention group consumed meats, eggs, dark green leafy vegetables, fruits, cooking oils and beans than did controls at 6, 9 and 12 months. By 12 months, more infants in the intervention group than controls received all food groups except for grains. The biggest differences were found in the percentage consuming meats or organ meats $(96 \cdot 9 \% v .58 \cdot 2 \%$, $P<0.001)$, beans $(92 \cdot 1 \% v \cdot 67 \cdot 2 \%, P<0.001)$ and yellow or orange foods $(97 \cdot 2 \% v \cdot 76 \cdot 7 \%, P<0 \cdot 001)$. Children in the intervention group had more meals (semi-solid or solid foods) per day than did their counterparts at 6 months (1.60 v. 1.05, $P<0 \cdot 001), 9$ months (3.77 v. $2 \cdot 53, P<0.001)$ and 12 months ( $4 \cdot 19$ v. $2 \cdot 90, P<0 \cdot 001$; Table 2$)$.

At 6 and 12 months, more mothers in the intervention group reported that they washed their own hands and their children's hands before meals than did mothers in the control group. They were also more likely to wash hands using soap and clean water than mothers in the control group. More mothers in the intervention group than the control group cooked easy-to-digest foods separately for their children and encouraged children to eat when they refused food (Table 2).

Infant growth results are shown in Table 3. At baseline, there were no significant differences in the mean weights and lengths between the intervention and control groups (weight: $6.51 v .6 .66 \mathrm{~kg}, \quad P=0.09$; length: $60.75 v$. $61 \cdot 10 \mathrm{~cm}, P=0 \cdot 17)$. By the age of 12 months, the intervention group reached a mean weight of $9 \cdot 70 \mathrm{~kg}$ and a 
Table 1 Characteristics of children and their households at baseline: healthy infants ( $n$ 599), aged 2-4 months at baseline (AprilSeptember 2006), from eight townships in Laishui County of Hebei Province, rural north-west China

\begin{tabular}{|c|c|c|c|c|}
\hline \multirow[b]{2}{*}{ Characteristic } & \multicolumn{2}{|c|}{ Intervention ( $n$ 294) } & \multicolumn{2}{|c|}{ Control (n 305) } \\
\hline & $n$ or Mean & $\%$ or SD & $n$ or Mean & $\%$ or $\mathrm{sL}$ \\
\hline \multicolumn{5}{|l|}{ Child } \\
\hline \multicolumn{5}{|l|}{$\operatorname{Sex}(n, \%)$} \\
\hline Male & 142 & $48 \cdot 3$ & 162 & $53 \cdot 1$ \\
\hline Female & 152 & $51 \cdot 7$ & 143 & $46 \cdot 9$ \\
\hline Age (months) & $2 \cdot 7$ & 0.5 & $2 \cdot 8$ & 0.6 \\
\hline Birth weight (g) & $3308 \cdot 8$ & 431.5 & $3271 \cdot 7$ & $470 \cdot 8$ \\
\hline Birth length $(\mathrm{cm})$ & $49 \cdot 8$ & $1 \cdot 9$ & $49 \cdot 9$ & $1 \cdot 7$ \\
\hline \multicolumn{5}{|l|}{ Parents and household } \\
\hline Mother's age (years) & $27 \cdot 2$ & $4 \cdot 3$ & $26 \cdot 6$ & $4 \cdot 4$ \\
\hline Father's age (years) & $27 \cdot 7$ & $4 \cdot 2$ & $27 \cdot 7$ & $4 \cdot 3$ \\
\hline \multicolumn{5}{|l|}{ Mother's ethnicity $(n, \%)$} \\
\hline Han & 286 & $97 \cdot 3$ & 291 & $95 \cdot 4$ \\
\hline Minority & 8 & $2 \cdot 7$ & 14 & $4 \cdot 6$ \\
\hline \multicolumn{5}{|l|}{ Father's ethnicity $(n, \%)$} \\
\hline Han & 289 & $98 \cdot 3$ & 290 & $95 \cdot 1$ \\
\hline Minority & 4 & $1 \cdot 4$ & 13 & $4 \cdot 3$ \\
\hline \multicolumn{5}{|l|}{ Mother's employment ${ }^{\star}(n, \%)$} \\
\hline Migrant workert & 81 & $27 \cdot 6$ & 84 & $27 \cdot 5$ \\
\hline Farmer & 168 & $57 \cdot 1$ & 152 & $49 \cdot 8$ \\
\hline Business & 17 & $5 \cdot 8$ & 33 & $10 \cdot 8$ \\
\hline Public sectors $\ddagger$ & 28 & $9 \cdot 5$ & 36 & $11 \cdot 8$ \\
\hline \multicolumn{5}{|l|}{ Father's employment ${ }^{*}(n, \%)$} \\
\hline Migrant workert & 198 & $67 \cdot 3$ & 170 & $55 \cdot 7$ \\
\hline Farmer & 44 & $15 \cdot 0$ & 44 & $14 \cdot 4$ \\
\hline Business & 24 & $8 \cdot 2$ & 59 & $19 \cdot 3$ \\
\hline Public sectorsł & 28 & $9 \cdot 5$ & 32 & $10 \cdot 5$ \\
\hline \multicolumn{5}{|l|}{ Mother's education ( $n, \%)$} \\
\hline Primary school $1-3$ grade or less & 6 & $2 \cdot 0$ & 8 & $2 \cdot 6$ \\
\hline Primary school 4-6 grade & 45 & $15 \cdot 3$ & 42 & $13 \cdot 8$ \\
\hline Junior high school & 202 & $68 \cdot 7$ & 218 & $71 \cdot 4$ \\
\hline High school or above & 37 & $12 \cdot 6$ & 35 & $11 \cdot 4$ \\
\hline \multicolumn{5}{|l|}{ Father's education ( $n, \%)$} \\
\hline Primary school $1-3$ grade or less & 1 & $0 \cdot 3$ & 3 & $1 \cdot 0$ \\
\hline Primary school 4-6 grade & 21 & $7 \cdot 1$ & 23 & $7 \cdot 5$ \\
\hline Junior high school & 223 & $75 \cdot 9$ & 230 & $75 \cdot 4$ \\
\hline High school or above & 42 & $14 \cdot 3$ & 45 & $14 \cdot 7$ \\
\hline \multicolumn{5}{|l|}{ Number of siblings $(n, \%)$} \\
\hline 1 & 189 & $64 \cdot 3$ & 200 & $65 \cdot 6$ \\
\hline 2 or more & 105 & $35 \cdot 7$ & 105 & $34 \cdot 4$ \\
\hline \multicolumn{5}{|l|}{ Number of possessions $\$(n, \%)$} \\
\hline $0-1$ & 6 & $2 \cdot 0$ & 6 & $2 \cdot 0$ \\
\hline $2-4$ & 163 & $55 \cdot 4$ & 148 & $48 \cdot 5$ \\
\hline $5-6$ & 125 & $42 \cdot 5$ & 151 & $49 \cdot 5$ \\
\hline Mother's weight $(\mathrm{kg})$ & 63.9 & $9 \cdot 6$ & $63 \cdot 8$ & $9 \cdot 8$ \\
\hline Father's weight $(\mathrm{kg})$ & $69 \cdot 8$ & $11 \cdot 3$ & 68.9 & $10 \cdot 1$ \\
\hline Mother's height $(\mathrm{cm})$ & $159 \cdot 6$ & $4 \cdot 8$ & $159 \cdot 1$ & $7 \cdot 3$ \\
\hline Father's height $(\mathrm{cm})$ & $171 \cdot 5$ & $4 \cdot 5$ & $171 \cdot 8$ & $4 \cdot 7$ \\
\hline
\end{tabular}

Data are number and percentage $(n, \%)$ or mean and standard deviation.

${ }^{*} P<0.05$ for mother's employment: Farmer and Business; Father's employment: Migrant worker and Business.

+Farmers leave the village and work temporarily in urban areas, usually working in construction, in factories or as domestic helpers.

¥Working at state-owned factories, education or health-care sectors, or government.

§Refrigerator, television set, cable television, VCR/DVD player, radio and telephone.

mean length of $74.70 \mathrm{~cm}, 0.06 \mathrm{~kg}$ heavier and $0.21 \mathrm{~cm}$ longer than controls; these differences were not statistically significant $(95 \% \mathrm{CI}:-0 \cdot 15,0 \cdot 28 \mathrm{~kg}, P=0 \cdot 56$; and $-0 \cdot 29,0 \cdot 71 \mathrm{~cm}, P=0 \cdot 4$, respectively).

The intervention group, however, gained more weight and length over the study period. Infants in the intervention group increased $3 \cdot 26 \mathrm{~kg}$ in mean weight and $14 \cdot 16 \mathrm{~cm}$ in mean length between baseline and 12 months of age, whereas the control group increased $3.02 \mathrm{~kg}$ in mean weight and $13.47 \mathrm{~cm}$ in mean length. The inter- vention group gained $0.24 \mathrm{~kg}$ more weight $(95 \% \mathrm{CI} 0 \cdot 02$, $0.46 \mathrm{~kg}, P=0.03)$ and $0.69 \mathrm{~cm}$ more length $(95 \% \mathrm{CI} 0.10$, $1 \cdot 28 \mathrm{~cm}, P=0.02$ ) than did controls (Table 3). Effects of the intervention on incremental weight and length remained significant after adjusting for infants' and parents' sociodemographic covariates. The multivariate regression results show that the intervention group gained $0.22 \mathrm{~kg}$ more weight $(95 \%$ CI $0.003,0.45 \mathrm{~kg}$, $P=0.047)$ and gained $0.66 \mathrm{~cm}$ more length $(95 \% \mathrm{CI} 0.03$, $1.29 \mathrm{~cm}, P=0.04$; Table 3 ). We further adjusted for the 


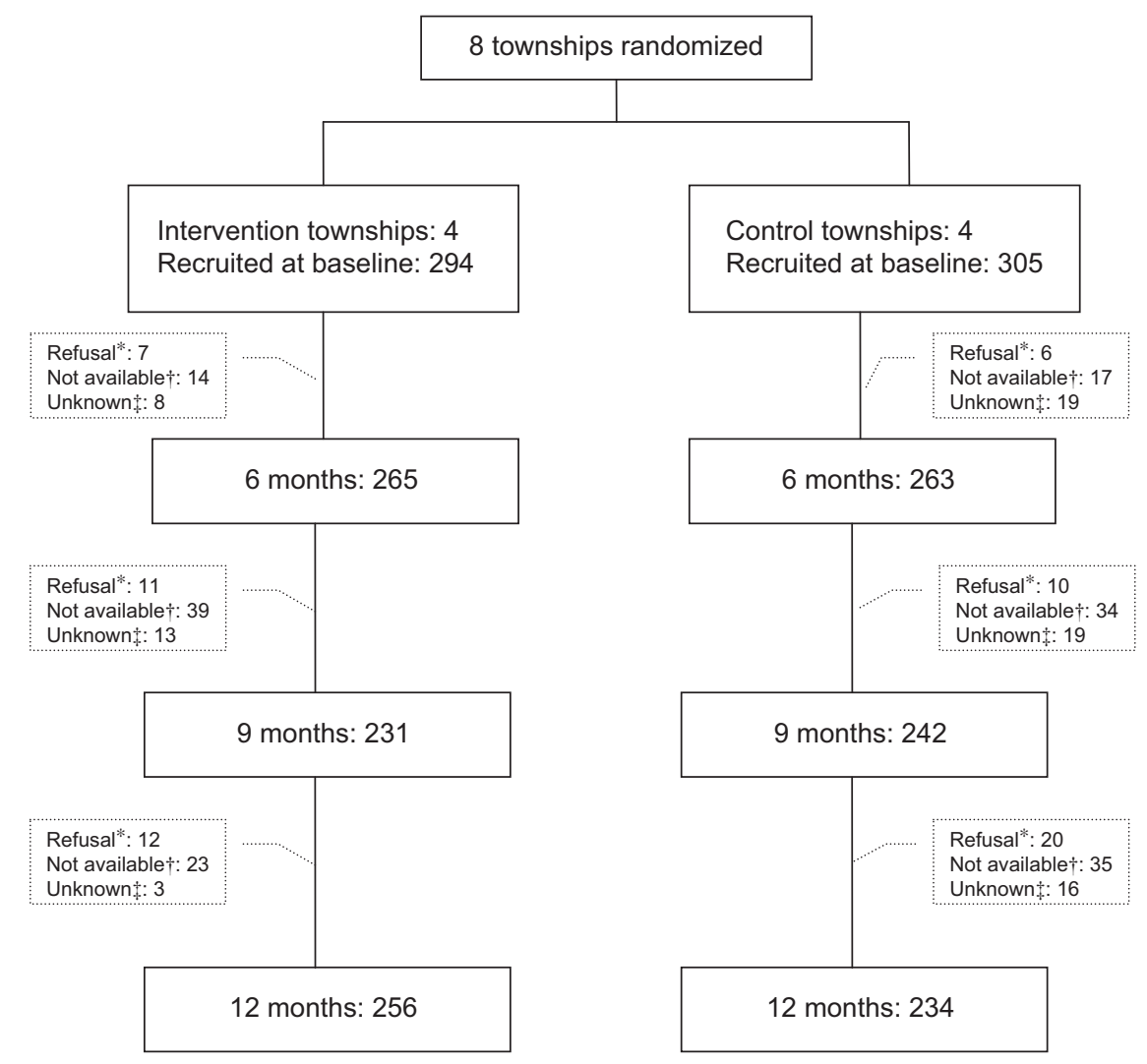

Fig. 1 Trial profile ( ${ }^{*}$ Refusal: the subject decided not to participate; $\dagger$ Not available: the subject moved out of the area or was not at home at the time of the survey; IUnknown: the subject dropped out of the study while the interviewer did not record the reason for drop-out)

infants' initial weight or length and age at baseline, but the results did not change substantially for weight increment $(0 \cdot 20 \mathrm{~kg}, 95 \% \mathrm{CI}-0 \cdot 02,0 \cdot 42 \mathrm{~kg}, P=0 \cdot 08)$ or length increment $(0.66 \mathrm{~cm}, 95 \% \mathrm{CI} 0.06,1.27 \mathrm{~cm}, P=0.03)$.

Random-effect models were used to examine the effect of the intervention on growth over time adjusting for correlations within subjects across observation points. The intervention group attained faster growth velocities in weight (0.04 kg/month, 95\% CI $0.02,0.06 \mathrm{~kg} /$ month, $P<0 \cdot 001)$ and length $(0 \cdot 11 \mathrm{~cm} /$ month, $95 \%$ CI $0 \cdot 05,0 \cdot 17 \mathrm{~cm} / \mathrm{month}$, $P<0 \cdot 001)$. As shown in Fig. 2, the intervention group gained weight and length more quickly than did controls.

\section{Discussion}

Our findings show that an educational intervention delivered through local health-care providers can effectively change caregivers' complementary feeding practices and improve infants' growth status. The intervention activities in the current study were culturally sensitive, comprehensive, and integrated with local resources. When developing the intervention plan, we evaluated how traditional complementary foods were prepared, whether local foods were sufficient to meet nutrient requirements, and whether the recipes were acceptable, affordable and convenient for local families. The educational messages were simple, focused and illustrated. A key element in the success of the study is that the intervention was implemented through existing health-care services. Over $80 \%$ of the surveyed mothers ranked health-care providers as their most trusted source of information on child care and feeding. In addition, health-care providers have ready access to local families through routine health services, which makes them the most viable resource to deliver the intervention. Thus, integrating educational activities on complementary feeding into the existing health-care system may result in greater sustainability over the long term.

The intervention group showed greater incremental growth, of the order of $0.24 \mathrm{~kg}$ and $0.69 \mathrm{~cm}$, from $2-4$ to 12 months of age. Although not strictly comparable, this improvement in linear growth is consistent with the summary effect on linear growth of $1 \cdot 14 \mathrm{~cm}$ from 6 to 18 months for comparable educational interventions reported by Bhutta et al. in the recent Lancet series on maternal and child undernutrition ${ }^{(21)}$. There were no significant differences observed in attained weight and length between group, but the intervention group was somewhat lighter and shorter than the control group at baseline 


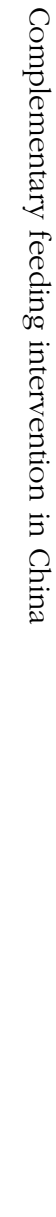

Table 2 Infant feeding practices at each follow-up point by treatment: healthy infants, aged 2-4 months at baseline (April-September 2006), from eight townships in Laishui County of Hebei Province, rural north-west China

\begin{tabular}{|c|c|c|c|c|c|c|c|c|c|c|c|c|c|c|c|c|c|c|c|c|}
\hline & \multicolumn{5}{|c|}{ 2-4 months* } & \multicolumn{5}{|c|}{6 monthst } & \multicolumn{5}{|c|}{9 monthsł } & \multicolumn{5}{|c|}{12 months $\S$} \\
\hline & \multicolumn{2}{|c|}{ Intervention } & \multicolumn{2}{|c|}{ Control } & \multirow[b]{2}{*}{$P$} & \multicolumn{2}{|c|}{ Intervention } & \multicolumn{2}{|c|}{ Control } & \multirow[b]{2}{*}{$P$} & \multicolumn{2}{|c|}{ Intervention } & \multicolumn{2}{|c|}{ Control } & \multirow[b]{2}{*}{$P$} & \multicolumn{2}{|c|}{ Intervention } & \multicolumn{2}{|c|}{ Control } & \multirow[b]{2}{*}{$P$} \\
\hline & $\begin{array}{l}n \text { or } \\
\text { Mean }\end{array}$ & $\begin{array}{l}\% \text { or } \\
\text { SD }\end{array}$ & $\begin{array}{l}n \text { or } \\
\text { Mean }\end{array}$ & $\begin{array}{c}\% \text { or } \\
\text { SD }\end{array}$ & & $\begin{array}{l}n \text { or } \\
\text { Mean }\end{array}$ & $\begin{array}{c}\% \text { or } \\
\text { SD }\end{array}$ & $\begin{array}{l}n \text { or } \\
\text { Mean }\end{array}$ & $\begin{array}{l}\% \text { or } \\
\text { SD }\end{array}$ & & $\begin{array}{l}n \text { or } \\
\text { Mean }\end{array}$ & $\begin{array}{c}\% \text { or } \\
\text { SD }\end{array}$ & $\begin{array}{l}n \text { or } \\
\text { Mean }\end{array}$ & $\begin{array}{l}\% \text { or } \\
\text { SD }\end{array}$ & & $\begin{array}{l}n \text { or } \\
\text { Mean }\end{array}$ & $\begin{array}{l}\% \text { or } \\
\text { SD }\end{array}$ & $\begin{array}{l}n \text { or } \\
\text { Mean }\end{array}$ & $\begin{array}{l}\% \text { or } \\
\text { SD }\end{array}$ & \\
\hline $\begin{array}{l}\text { Currently breast-feeding } \\
(n, \%)\end{array}$ & 284 & $96 \cdot 6$ & 288 & $94 \cdot 4$ & $0 \cdot 21$ & 248 & $93 \cdot 6$ & 247 & $93 \cdot 9$ & $0 \cdot 88$ & 217 & $93 \cdot 9$ & 228 & $94 \cdot 6$ & $0 \cdot 76$ & 217 & $85 \cdot 1$ & 199 & $85 \cdot 4$ & 0.92 \\
\hline Breast-feeding frequency & $8 \cdot 87$ & $2 \cdot 58$ & $8 \cdot 97$ & $2 \cdot 85$ & 0.33 & $7 \cdot 66$ & $2 \cdot 28$ & $7 \cdot 40$ & $2 \cdot 33$ & $0 \cdot 20$ & $7 \cdot 30$ & $2 \cdot 20$ & 8.00 & $2 \cdot 75$ & 0.004 & $6 \cdot 61$ & $2 \cdot 12$ & $7 \cdot 48$ & $1 \cdot 83$ & $0 \cdot 36$ \\
\hline \multicolumn{21}{|l|}{ Ever been fed $(n, \%)$ : } \\
\hline Bread, rice, noodles & 6 & $2 \cdot 0$ & 13 & $4 \cdot 3$ & 0.12 & 214 & $80 \cdot 8$ & 155 & 58.9 & $<0.001$ & 228 & $99 \cdot 1$ & 233 & $96 \cdot 3$ & 0.04 & 254 & $100 \cdot 0$ & 229 & $98 \cdot 3$ & $0 \cdot 11$ \\
\hline Roots or tubers & 0 & 0 & 0 & 0 & $1 \cdot 00$ & 65 & $24 \cdot 5$ & 61 & $23 \cdot 2$ & 0.72 & 187 & $81 \cdot 7$ & 178 & $73 \cdot 6$ & 0.04 & 231 & $90 \cdot 9$ & 172 & $73 \cdot 8$ & $<0.001$ \\
\hline Yellow/orange foods & 3 & $1 \cdot 0$ & 8 & $2 \cdot 6$ & $0 \cdot 14$ & 126 & $47 \cdot 6$ & 100 & $38 \cdot 0$ & 0.03 & 213 & $92 \cdot 6$ & 194 & $80 \cdot 2$ & $<0.001$ & 247 & $97 \cdot 2$ & 178 & $76 \cdot 7$ & $<0.001$ \\
\hline Green leafy vegetables & 0 & 0 & 2 & 0.7 & 0.16 & 95 & $35 \cdot 9$ & 53 & $20 \cdot 2$ & $<0.001$ & 216 & 93.9 & 188 & $77 \cdot 7$ & $<0.001$ & 248 & $97 \cdot 6$ & 204 & $87 \cdot 9$ & $<0.001$ \\
\hline Beans/peas/lentils & 0 & 0 & 0 & 0 & $1 \cdot 00$ & 96 & $36 \cdot 2$ & 43 & $16 \cdot 4$ & $<0.001$ & 203 & $88 \cdot 3$ & 149 & $61 \cdot 6$ & $<0.001$ & 234 & $92 \cdot 1$ & 156 & $67 \cdot 2$ & $<0.001$ \\
\hline Fruits & 23 & $7 \cdot 8$ & 24 & $7 \cdot 9$ & 0.98 & 211 & $79 \cdot 6$ & 181 & $68 \cdot 8$ & $<0.001$ & 229 & $99 \cdot 6$ & 231 & $95 \cdot 5$ & 0.005 & 253 & $99 \cdot 6$ & 224 & $96 \cdot 6$ & 0.04 \\
\hline Eggs & 5 & $1 \cdot 7$ & 6 & $2 \cdot 0$ & 0.81 & 220 & $83 \cdot 0$ & 172 & $65 \cdot 4$ & $<0.001$ & 227 & $98 \cdot 7$ & 229 & $94 \cdot 6$ & 0.02 & 252 & $98 \cdot 8$ & 214 & $92 \cdot 2$ & 0.002 \\
\hline Meat or organ meats & 0 & 0 & 0 & 0 & 1.00 & 80 & $30 \cdot 3$ & 28 & $10 \cdot 7$ & $<0.001$ & 211 & $91 \cdot 7$ & 137 & $56 \cdot 6$ & $<0.001$ & 246 & $96 \cdot 9$ & 135 & $58 \cdot 2$ & $<0.001$ \\
\hline Cooking oil/fats & 1 & 0.3 & 0 & 0 & 0.31 & 87 & $32 \cdot 8$ & 45 & $17 \cdot 2$ & $<0.001$ & 207 & $90 \cdot 0$ & 183 & $75 \cdot 6$ & $<0.001$ & 245 & $96 \cdot 5$ & 185 & $79 \cdot 7$ & $<0.001$ \\
\hline Meal frequency & - & & - & & - & $1 \cdot 62$ & $1 \cdot 50$ & 1.05 & $1 \cdot 18$ & $<0.001$ & $3 \cdot 77$ & $1 \cdot 62$ & $2 \cdot 53$ & $1 \cdot 82$ & $<0.001$ & $4 \cdot 17$ & & $2 \cdot 90$ & $1 \cdot 85$ & $<0.001$ \\
\hline Cook for child $(n, \%)$ & - & & - & & - & 104 & $39 \cdot 3$ & 60 & $22 \cdot 8$ & $<0.001$ & 55 & $23 \cdot 8$ & 28 & $11 \cdot 6$ & $<0.001$ & 68 & $26 \cdot 6$ & 46 & $18 \cdot 7$ & 0.07 \\
\hline $\begin{array}{l}\text { Wash hands before feeding } \\
(n, \%)\end{array}$ & 134 & $45 \cdot 6$ & 126 & $41 \cdot 3$ & 0.29 & 154 & $58 \cdot 1$ & 119 & $45 \cdot 3$ & 0.003 & - & & - & & - & 206 & $80 \cdot 5$ & 159 & $67 \cdot 9$ & 0.001 \\
\hline $\begin{array}{l}\text { Use soap and clean water for } \\
\text { washing hands }(n, \%)\end{array}$ & - & & - & & - & 138 & $52 \cdot 1$ & 112 & $42 \cdot 6$ & 0.03 & - & & - & & - & 160 & $62 \cdot 5$ & 105 & 44.9 & $<0.001$ \\
\hline $\begin{array}{l}\text { Encourage child to eat when } \\
\text { child refuses }(n, \%)\end{array}$ & - & & - & & - & - & & - & & - & 140 & $60 \cdot 6$ & 41 & $16 \cdot 9$ & $<0.001$ & - & & - & & - \\
\hline
\end{tabular}

Data are number and percentage $(n, \%)$ or mean and standard deviation.

- indicates data not available because the item was not asked at the survey.

*Intervention group $n$ 294, control group $n 305$.

tIntervention group $n 265$, control group $n 263$.

tintervention group $n$ 265, control group $n 263$.

\$Intervention group $n 256$, control group $n 234$. 
Table 3 Child growth by treatment group: healthy infants, aged 2-4 months at baseline (April-September 2006), from eight townships in Laishui County of Hebei Province, rural north-west China

\begin{tabular}{|c|c|c|c|c|c|c|c|c|c|c|}
\hline & \multicolumn{2}{|c|}{ Intervention } & \multicolumn{2}{|c|}{ Control } & \multicolumn{2}{|c|}{ Unadjusted difference } & \multirow[b]{2}{*}{$P$} & \multicolumn{2}{|c|}{ Adjusted difference* } & \multirow[b]{2}{*}{$P$} \\
\hline & Mean & SD & Mean & SD & Mean & $95 \% \mathrm{Cl}$ & & Mean & $95 \% \mathrm{Cl}$ & \\
\hline \multicolumn{11}{|c|}{ At age $2-4$ monthst } \\
\hline Weight (kg) & $6 \cdot 51$ & 1.09 & $6 \cdot 66$ & $1 \cdot 05$ & $-0 \cdot 15$ & $-0.32,0.02$ & 0.09 & $-0 \cdot 14$ & $-0.31,0.04$ & $0 \cdot 13$ \\
\hline Length (cm) & $60 \cdot 75$ & $3 \cdot 15$ & $61 \cdot 10$ & $2 \cdot 89$ & -0.35 & $-0 \cdot 83,0 \cdot 14$ & $0 \cdot 17$ & $-0 \cdot 31$ & $-0 \cdot 81,0 \cdot 18$ & 0.22 \\
\hline \multicolumn{11}{|c|}{ At age 6 months $\ddagger$} \\
\hline Weight (kg) & $8 \cdot 21$ & $1 \cdot 04$ & $8 \cdot 24$ & $1 \cdot 05$ & -0.03 & $-0.22,0.14$ & 0.69 & -0.01 & $-0 \cdot 19,0 \cdot 17$ & 0.92 \\
\hline Length (cm) & $67 \cdot 12$ & $2 \cdot 62$ & $67 \cdot 22$ & $2 \cdot 61$ & $-0 \cdot 10$ & $-0.55,0.35$ & 0.65 & -0.05 & $-0.49,0.39$ & 0.82 \\
\hline \multicolumn{11}{|c|}{ At age 9 months $\S$} \\
\hline Weight (kg) & $9 \cdot 15$ & $1 \cdot 07$ & $9 \cdot 06$ & $1 \cdot 12$ & 0.09 & $-0 \cdot 11,0 \cdot 30$ & 0.38 & $0 \cdot 15$ & $-0.05,0.36$ & $0 \cdot 14$ \\
\hline Length (cm) & $70 \cdot 66$ & $2 \cdot 49$ & $71 \cdot 28$ & $2 \cdot 92$ & -0.62 & $-1 \cdot 13,-0 \cdot 11$ & 0.02 & -0.50 & $-1 \cdot 01,0.01$ & 0.05 \\
\hline \multicolumn{11}{|c|}{ At age 12 monthsll } \\
\hline Weight $(\mathrm{kg})$ & $9 \cdot 70$ & $1 \cdot 25$ & $9 \cdot 64$ & $1 \cdot 16$ & 0.06 & $-0 \cdot 15,0.28$ & 0.56 & 0.03 & $-0.19,0.24$ & $0 \cdot 81$ \\
\hline Length (cm) & $74 \cdot 70$ & $2 \cdot 84$ & $74 \cdot 49$ & $2 \cdot 76$ & $0 \cdot 21$ & $-0 \cdot 29,0 \cdot 71$ & $0 \cdot 40$ & $0 \cdot 19$ & $-0.32,0.69$ & 0.46 \\
\hline \multicolumn{11}{|c|}{ Increment between baseline and 12 months } \\
\hline Weight (kg) & $3 \cdot 26$ & $1 \cdot 26$ & $3 \cdot 02$ & $1 \cdot 01$ & 0.24 & $0.02,0.46$ & 0.03 & $0 \cdot 22$ & $0.003,0.45$ & 0.047 \\
\hline Length (cm) & $14 \cdot 16$ & $3 \cdot 48$ & $13 \cdot 47$ & $2 \cdot 69$ & 0.69 & $0 \cdot 10,1 \cdot 28$ & 0.02 & $0 \cdot 66$ & $0.03,1.29$ & 0.04 \\
\hline
\end{tabular}

*Adjusted for infant's gender and number of siblings, and parents' age, ethnicity, education, employment and household possessions.

tIntervention group $n$ 287, control group $n 302$.

łIntervention group $n 258$, control group $n 254$.

\$Intervention group $n 214$, control group $n 227$.

IIIntervention group $n 256$, control group $n 234$.

ๆIntervention group $n 234$, control group $n 203$

(although the difference was not statistically significant) and became heavier and longer by the age of 12 months (again the difference was not statistically significant). Given a longer follow-up period, perhaps we would have been able to observe improvements in attained weight and length in the intervention compared with the control group. The results from this study confirmed the finding by Bhutta et al. that nutritional education alone can increase linear growth in food-secure populations, which was defined by an average income of at least $\$$ US 1 per person per day ${ }^{(21)}$.

The study indicated that more infants in the intervention group were fed diverse food groups, including meats or organ meats, eggs, fruits, vegetables, beans, roots, tubers and cooking oil. One of the key messages delivered to caregivers was that young children should be given animal-source protein such as meats, fish and eggs. We found that families with infants were resistant at first to the recommended recipe made from flour, egg, meat, green leafy vegetables, potato and cooking oil because they believed that 'the baby doesn't like egg or vegetables' and that 'egg, meat and cooking oil cannot be digested by the baby'. But after seeing how the recipe was prepared and how well their children accepted it during the recipe preparation demonstration, many of them agreed to try the recipe at home. By explicitly explaining the benefits of specific foods on child growth and addressing their concerns about feasibility, time and cost of preparing the recipes, the intervention changed caregivers' food selection behaviours. The results showed that $96.9 \%$ of infants in the intervention group were fed meats or organ meats at age 12 months, nearly double that reported by the control group (58.2\%). Findings from previous observational and randomised controlled studies have shown positive effects of animal-source foods on child growth and cognitive development ${ }^{(22-25)}$, and therefore researchers have advocated the use of animal-source food to address maternal and child malnutrition problems in developing countries ${ }^{(26)}$. In October 2008, the WHO re-emphasised the role of the animalsource foods as the first and most effective choice to treat moderately malnourished children,(27). In our study, improvements in linear growth were achieved by educating and motivating families to regularly incorporate animal-source foods that were available and affordable, but were not usually fed to infants. Although this strategy is dependent on adequate family resources to acquire such foods, the findings here suggest that interventions to incorporate more animal-source foods in the diets of older infants can be an important component of policies to improve growth in the first year of life.

The current study is the first randomised controlled trial of an education intervention on complementary feeding practices in China. Although problematic complementary feeding is universal in rural areas due to socio-economic constraints and traditional beliefs, there is a severe paucity of studies on complementary feeding in China. Only two educational intervention studies in China have been published. One study was conducted in Sichuan, a southern province in China, which disseminated nutrition education messages and enhanced recipes to families with infants aged 4 to 12 months ${ }^{(6)}$. The intervention group was heavier and longer than the control group after implementation of the intervention. However, the study was not a randomised controlled design and did not collect baseline information, which prohibited examination 

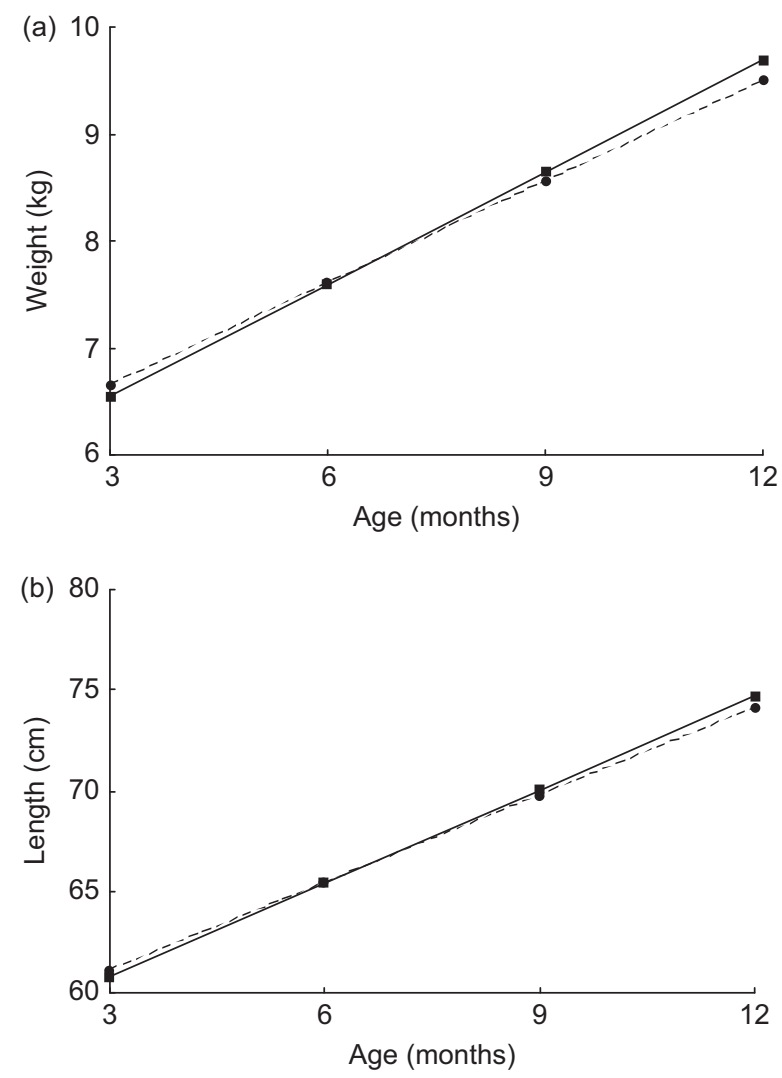

Fig. 2 Infant growth in (a) weight $(\mathrm{kg})$ and $(\mathrm{b})$ length $(\mathrm{cm})$ from baseline to 12 months of age in the intervention (- - ) and control (- - - - ) groups: healthy infants (n 599), aged 2-4 months at baseline (April-September 2006), from eight townships in Laishui County of Hebei Province, rural north-west China

of the causal effects of the intervention on child growth ${ }^{(6)}$. The other study was conducted among infants of Dai minority in Yunnan Province ${ }^{(17)}$. That study employed nutrition education, growth monitoring, cooking demonstration and integrated management of childhood diseases as intervention approaches and found improved weights among male infants. However, the study had a cross-sectional design and the weights were compared among two different groups of children at pre- and post-intervention time periods ${ }^{(17)}$. These methodological problems limited the validity of the study results. Our study avoided these potential pitfalls. The strengths of our study are the randomised controlled design, well-trained and supervised field workers, standardised evaluation procedures, and a carefully designed data analysis plan to take into account the clustering nature of the data.

Our study also has some limitations. First, about $20 \%$ of participants dropped out during the study period. Many rural labourers poured into cities for jobs because of the huge inequality in social and economic development between the rural and urban areas in China. It is difficult to avoid drop-outs although the field workers made great efforts to maintain the participants in the study. However, the families lost to follow-up were not significantly different from those who remained in the study with respect to baseline sociodemographic characteristics. Therefore we do not think that the loss to follow-up caused significant selection bias in our study. Second, dietary data in the study such as breast-feeding frequency, meal frequency and consumption of different food groups were obtained from a $24 \mathrm{~h}$ dietary recall. According to findings from previous studies, parents of infants report their infant's inhome dietary intakes accurately, and data obtained by the dietary recall can be highly consistent with weighed food intakes ${ }^{(28)}$. Researchers in China compared children's daily energy intake obtained from the $24 \mathrm{~h}$ dietary recall with data from a $3 \mathrm{~d}$ household inventory, the standard approach, and found only a $1 \%$ difference between the two methods ${ }^{(29)}$. We have no data on accuracy and reliability of our dietary measures, but the body of research supports its use as an adequate method for assessing food consumption in populations, including infants.

Another concern is possible information bias caused by the inability to blind people to the treatment assignment. For a randomised controlled study, ideally the people who evaluate the outcomes should not be the same people who administer the intervention. These people, together with the participants, should be blind to treatment assignment. In the current study, due to the shortage of health-care staff, those people conducting questionnaire survey and anthropometric measurement were the same ones who delivered the intervention, and they were aware of the treatment assignment. The study participants were also aware of their treatment as it was clearly stated in the consent procedure. However, we believe that this should not have introduced information bias because the anthropometric outcomes were objective. In addition, we implemented strict training, supervision and quality control measures. Weight and length scales were centrally purchased and distributed to the township hospitals, and were calibrated by the supervisors from Peking University every month. Before the study was launched, all examiners were gathered at the county hospital and trained on standardised measurement techniques. After the training, the trainees were asked to measure weights and lengths of twelve children, three times for each child. The validity of anthropometric measurements was evaluated by comparing the readings of the trainees with those made by the supervisor. The intra-observer reliability was measured by the coefficient of reliability. After the training session, all observers reached a coefficient of reliability greater than 0.95 . During the study, supervisors from Peking University and the county hospital conducted supervision every month on the observers' practice of measuring children's weight and length. The inter-observer reliability was 0.98 for weight and 0.93 for length. If there was more than $0.1 \mathrm{~kg}$ difference in weight and more than $1.0 \mathrm{~cm}$ in length between two measurements, additional measurement would be taken until the difference was within $0 \cdot 1 \mathrm{~kg}$ for 
weight and $1.0 \mathrm{~cm}$ for length. The average of the two measurements was used as the final value of measurement. These approaches should have ensured the quality of outcome measurement.

The findings from our study, combined with the positive findings from other studies, provide promising evidence about the effects of educational interventions on complementary feeding practices and infant nutritional status. Further study is needed to determine the sustainability of such intervention effects on child growth and nutrition, and to assess the generalisability of the intervention to similar areas in China and other developing countries.

\section{Acknowledgements}

The study was funded by the Proctor \& Gamble Fellowship provided through the Johns Hopkins Bloomberg School of Public Health. The funding source had no role in the study design, data analysis, interpretation of data, writing of the report, or in the decision to submit the paper for publication. The authors do not have any financial, personal or professional conflicts of interest. L.S. contributed to study design, data analysis and drafting of the manuscript. J.Z. contributed to study design, data collection and data analysis. Y.W., L.E.C. and B.G. contributed to critical revision of the manuscript.

\section{References}

1. Dewey KG (2001) The challenges of promoting optimal infant growth. J Nutr 131, 1879-1880.

2. Bhandari N, Mazumder S, Bahl R, Martines J, Black RE \& Bhan MK; Infant Feeding Study Group (2004) An educational intervention to promote appropriate complementary feeding practices and physical growth in infants and young children in rural Haryana, India. J Nutr 134, 2342-2348.

3. Chen C (2000) Fat intake and nutritional status of children in China. Am J Clin Nutr 72, 5 Suppl., 1368S-1372S.

4. Chinese Ministry of Health (2004) A Study on Young Children's Nutrition and Health in Eight Provinces in China. Beijing: Department of Maternal and Child Health, Chinese Ministry of Health.

5. Zhai FY \& He YN (2001) Complementary feeding practice in Chinese rural children. Wei Sheng Yan Jiu 30, 305-308.

6. Guldan GS, Fan HC, Ma X, Ni ZZ, Xiang X \& Tang MZ (2000) Culturally appropriate nutrition education improves infant feeding and growth in rural Sichuan, China. J Nutr 130, 1204-1211.

7. Wang XL, Wang Y \& Shi L (2000) Analysis on breast-feeding and complementary feeding of children under 2 years of age in rural China. Chin J Child Health Care 8, 144-146.

8. Asian Development Bank (2008) Micronutrient Malnutrition Situation Analysis in China. Project Report. http://www. adb.org/Projects/Food-Fortification/cip-prc.pdf (accessed October 2008).

9. Caulfield LE, Huffman SL \& Piwoz EG (1999) Interventions to improve intake of complementary foods by infants 6 to 12 months of age in developing countries: impact on growth and on the prevalence of malnutrition and potential contribution to child survival. Food Nutr Bull 20, 183-200.
10. Kilaru A, Griffiths PL, Ganapathy S \& Ghosh S (2005) Community-based nutrition education for improving infant growth in rural Karnataka. Indian Pediatr 42, 425-432.

11. Penny ME, Creed-Kanashiro HM, Robert RC, Narro MR, Caulfield LE \& Black RE (2005) Effectiveness of an educational intervention delivered through the health services to improve nutrition in young children: a clusterrandomised controlled trial. Lancet 365, 1863-1872.

12. Santos I, Victora CG, Martines J, Gonçalves H, Gigante DP, Valle NJ \& Pelto G (2001) Nutrition counseling increases weight gain among Brazilian children. J Nutr 131, 2866-2873.

13. Salehi M, Kimiagar SM, Shahbazi M, Mehrabi Y \& Kolahi AA (2004) Assessing the impact of nutrition education on growth indices of Iranian nomadic children: an application of a modified beliefs, attitudes, subjective-norms and enabling-factors model. Br J Nutr 91, 779-787.

14. Bhandari N, Bahl R, Nayyar B, Khokhar P, Rohde JE \& Bhan MK (2001) Food supplementation with encouragement to feed it to infants from 4 to 12 months of age has a small impact on weight gain. J Nutr 131, 1946-1951.

15. Pachon H, Schroeder DG, Marsh DR, Dearden KA, Ha TT \& Lang TT (2002) Effect of an integrated child nutrition intervention on the complementary food intake of young children in rural north Viet Nam. Food Nutr Bull 23, 4 Suppl., 62-69.

16. Gartner A, Kameli Y \& Traissac P (2007) Has the first implementation phase of the Community Nutrition Project in urban Senegal had an impact? Nutrition 23, 219-228.

17. Li Y, Hotta M, Shi A, Li Z, Yin J, Guo G, Kawata K \& Ushijima H (2007) Malnutrition improvement for infants under 18 months old of Dai minority in Luxi, China. Pediatr Int 49, 273-279.

18. Hotz C \& Gibson R (2005) Participatory nutrition education and adoption of new feeding practices are associated with improved adequacy of complementary diets among rural Malawian children: a pilot study. Eur J Clin Nutr 59, 226-237.

19. Mackintosh UA, Marsh DR \& Schroeder DG (2002) Sustained positive deviant child care practices and their effects on child growth in Viet Nam. Food Nutr Bull 23, 4 Suppl., 18-27.

20. Cogill B (2003) Anthropometric Indicators Measurement Guide. Washington, DC: Food and Nutrition Technical Assistance Project, Academy for Educational Development.

21. Bhutta ZA, Ahmed T, Black RE et al:; Maternal and Child Undernutrition Study Group (2008) What works? Interventions for maternal and child undernutrition and survival. Lancet 371, 417-440.

22. Sanghvi T, Ameringzen MV, Baker J \& Fiedler J (2007) Vitamin and mineral deficiencies technical situation analysis: a report for the Ten Year Strategy for the Reduction of Vitamin and Mineral Deficiencies. Food Nutr Bull 28, 1 Suppl., S157-S219.

23. Grillenberger M, Neumann CG, Murphy SP, Bwibo NO, Weiss RE, Jiang L, Hautvast JG \& West CE (2006) Intake of micronutrients high in animal-source foods is associated with better growth in rural Kenyan school children. $\mathrm{BrJ}$ Nutr 95, 379-390.

24. Neumann CG, Bwibo NO, Murphy SP, Sigman M, Whaley S, Allen LH, Guthrie D, Weiss RE \& Demment MW (2003) Animal source foods improve dietary quality, micronutrient status, growth and cognitive function in Kenyan school children: background, study design and baseline findings. J Nutr 133, 11 Suppl. 2, 3941S-3949S.

25. Siekmann JH, Allen LH, Bwibo NO, Demment MW, Murphy SP \& Neumann CG (2003) Kenyan school children have multiple micronutrient deficiencies, but increased plasma vitamin B-12 is the only detectable micronutrient response 
to meat or milk supplementation. J Nutr 133, 11 Suppl. 2, 3972S-3980S.

26. Anon. (2003) Animal source foods to improve micronutrient nutrition and human function in developing countries. Proceedings of a conference. June 24-26, 2002. Washington, DC, USA. J Nutr 133, 11 Suppl. 2, 3875S-4061S.

27. World Health Organization (2008) Consultation on the dietary management of moderate malnutrition. http://www. who.int/nutrition/topics/severemalnutrition_consultation dietarymanagement/en/index.html (accessed March 2009).

28. Klesges RC, Klesges LM, Brown G \& Frank GC (1987) Validation of the 24-hour dietary recall in preschool children. J Am Diet Assoc 87, 1383-1385.

29. Zhai F, Guo X \& Popkin B (1996) Evaluation of the 24-hour individual recall method in China. Food Nutr Bull 17, 154-161. 